УДК 621.315 .592

\title{
Диффузия и взаимодействие In и As, имплантированных в пленки $\mathrm{SiO}_{2}$
}

\author{
(C) И.Е. Тысченко ${ }^{1}$, M. Voelskow ${ }^{2}$, A.Н. Михайлов ${ }^{3}$, Д.И. Тетельбаум ${ }^{3}$ \\ ${ }^{1}$ Институт фризики полупроводников им. А.В. Ржанова Сибирского отделения Российской академии наук, \\ 630090 Новосибирск, Россия \\ ${ }^{2}$ Institute of Ion-Beam Physics and Materials Research, Helmholtz-Center Dresden-Rossendorf, \\ D-01314 Dresden, Germany \\ ${ }^{3}$ Национальный исследовательский Нижегородский государственный университет им. Н.И. Лобачевского, \\ 603950 Нижний Новгород, Россия \\ E-mail: tys@isp.nsc.ru
}

Поступила в Редакцию 19 марта 2019 г.

В окончательной редакции 28 мартра 2019 г.

Принята к публикации 28 марта 2019 г.

\begin{abstract}
Методами резерфордовского обратного рассеяния, электронной микроскопии и энергодисперсионной рентгеновской спектроскопии изучено пространственное распределение и взаимодействие атомов In и As, имплантированных с концентрациями $\sim 1.5$ ат\% в термически выращенные пленки $\mathrm{SiO}_{2}$, в зависимости от температуры последующего отжига при $T=800-1100^{\circ} \mathrm{C}$ в потоке паров азота. Установлено, что после отжига при $T=800-900^{\circ} \mathrm{C}$ происходит сегрегация атомов As на глубине средних пробегов ионов $\mathrm{As}^{+}$и формирование нанокластеров As, которые являются стоками для атомов In. Увеличение температуры отжига до $1100^{\circ} \mathrm{C}$ приводит к сегрегации атомов In на поверхности $\mathrm{SiO}_{2}$ и одновременной ускоренной диффузии атомов мышьяка с коэффициентом $D_{\mathrm{As}}=3.2 \cdot 10^{-14} \mathrm{~cm}^{2} / \mathrm{c}$.
\end{abstract}

Ключевые слова: In, As, оксид кремния, ионная имплантация, диффузия.

DOI: 10.21883/FTP.2019.08.47989.9109

\section{1. Введение}

Кремниевая технология, базирующаяся на классической интеграции комплементарных транзисторов металл-диэлектрик-полупроводник, исчерпала возможности дальнейшего увеличения плотности элементов интегральных схем. Это обусловлено как технологическими, так и физическими ограничениями. Дальнейшее увеличение проектных норм становится нецелесообразным из-за того, что уже при достигнутых размерах масштабирования линейных размеров активные области транзисторов составляют несколько десятков атомов. Уменьшение размеров транзисторов накладывает в свою очередь ограничение и на скорость передачи информации, связанное с ростом паразитных емкостей, соответствующим увеличением пороговых напряжений и возрастающими потерями тепла. Один из возможных путей решения этих проблем видится в создании гибридных интегральных схем, объединяющих элементы с различными функциональными свойствами (электронными, фотонными, спиновыми и др.). Реализация таких схем требует создания новых многофункциональных материалов. В качестве таких материалов могут быть использованы кристаллы с пониженной размерностью соединений $\mathrm{A}^{\mathrm{III}} \mathrm{B}^{\mathrm{V}}$, интегрированные в единую кремниевую платформу [1-4]. Мотивация использования именно материалов нанокристаллов $\mathrm{A}^{\mathrm{III}} \mathrm{B}^{\mathrm{V}}$ основана на уникальных свойствах этих соединений $[5,6]$. Большинство соединений $\mathrm{A}^{\mathrm{III}} \mathrm{B}^{\mathrm{V}}$ является прямозонными полупроводниками.
Это определяет их высокую квантовую эффективность и применимость для создания оптоэлектронных приборов. Из всех соединений $\mathrm{A}^{\mathrm{III}} \mathrm{B}^{\mathrm{V}}$, InSb и InAs обладают рекордными значениями подвижности электронов, что делает возможным использование этих полупроводников для увеличения быстродействия интегральных схем [5]. $\mathrm{B}$ некоторых материалах $\mathrm{A}^{\mathrm{III}} \mathrm{B}^{\mathrm{V}}$ наблюдается достаточно большая величина спин-орбитального расщепления, что делает их весьма привлекательными с точки зрения создания приборов полупроводниковой спинтроники и последующего использования для квантовой обработки информации [7].

Создание гетероструктур соединений $\mathrm{A}^{\mathrm{III}} \mathrm{B}^{\mathrm{V}}$ на кремнии сопряжено с целым рядом трудностей, обусловленных большим рассогласованием решеток. В частности, для таких полупроводников, как $\mathrm{GaSb}, \mathrm{InP}, \mathrm{InAs}, \mathrm{InSb}$, оно составляет $8-19 \%$. Это означает, что создание таких структур эпитаксиальными методами может приводить к генерации большой плотности дислокаций несоответствия и соответствующей деградации их оптических и электронных свойств. Одним из универсальных методов создания гетероструктур на основе кремния является метод ионно-лучевого синтеза. В основе метода ионнолучевого синтеза лежат две операции, ионная имплантация и высокотемпературный отжиг, которые являются стандартными для имеющейся кремниевой технологии. Попытки ионного синтеза полупроводниковых соединений $\mathrm{A}^{\mathrm{III}} \mathrm{B}^{\mathrm{V}}$ предпринимались неоднократно [8-10]. Однако до недавнего времени эти попытки были эпизо- 
дическими, и лишь в последние годы появились целенаправленные исследования процессов ионного синтеза и свойств нанокристаллов соединений $\mathrm{A}^{\mathrm{III}} \mathrm{B}^{\mathrm{V}}$ в кремнии [11-13].

Соединения на основе индия, такие как InSb и InAs, обладают низкими значениями эффективной массы электронов и высокими значениями диэлектрической проницаемости, что делает возможным проявление в них квантово-размерного эффекта в широком диапазоне размеров. Это открывает перспективы их использования для создания оптической связи на кремнии. Ионный синтез нанокристаллов указанных соединений в оксиде кремния имеет целый ряд особенностей, обусловленных в первую очередь различием коэффициентов диффузии атомов III и V групп $[14,15]$. В предыдущих исследованиях [16] нами было показано, что ионный синтез нанокристаллов $\mathrm{InSb}$ в захороненных слоях $\mathrm{SiO}_{2}$ кремнийна-изоляторе (КНИ) структур происходит путем формирования преципитатов сурьмы, которые в последующем являются стоками для атомов индия и центрами зарождения новой фазы. Однако в открытых пленках $\mathrm{SiO}_{2}$ препятствием для взаимодействия атомов индия и элементов V группы может служить сток атомов In на поверхность. Поэтому в данной работе были изучены диффузия и взаимодействие атомов In и As, совместно имплантированных в пленки $\mathrm{SiO}_{2}$, при последующем отжиге.

\section{2. Методика экспериментов}

Пленки $\mathrm{SiO}_{2}$ толщиной $\sim 280$ нм были выращены термически на подложках монокристаллического кремния с ориентацией (100). Сначала имплантация пленок проводилась ионами $\mathrm{As}^{+}$c энергией 135 кэВ дозой $1 \cdot 10^{16} \mathrm{~cm}^{-2}$ на ионном ускорителе IMC-200. Плотность ионного тока составляла $0.5-0.6 \mathrm{M \kappa} / \mathrm{cm}^{2}$. Затем из пластины были вырезаны образцы размером $2 \times 2$ см и на ионно-лучевой установке ИЛУ-200 они были облучены ионами $\mathrm{In}^{+}$с энергией 50 кэВ дозой $4 \cdot 10^{15} \mathrm{~cm}^{-2}$. Плотность тока ионов составляла $0.4-0.7 \mathrm{мкA} / \mathrm{cm}^{2}$. Средний проецированный пробег ионов мышьяка $\left(R_{p}^{\mathrm{As}} \approx 100 \mathrm{Hм}\right)$ был в $\sim 2$ раза больше, чем пробег ионов индия $\left(R_{p}^{\mathrm{In}} \approx 40 \mathrm{Hм}\right)$. В каждом случае концентрация внедренных атомов в максимуме распределения, согласно предварительным расчетам по программе SRIM, составляла около 1.5 ат\%. После имплантации пластины были разрезаны на образцы прямоугольной формы, которые отжигались при температуре от 800 до $1100^{\circ} \mathrm{C}$ в течение 30 мин в потоке паров азота.

Анализ распределения атомов индия и мышьяка и структурные свойства имплантированных слоев исследовались методами спектрометрии резерфордовского обратного рассеяния (РОР), электронной микроскопия на поперечном срезе и энергодисперсионной рентгеновской спектроскопии (ЭДС). Профили распределения внедренных атомов исследовались с помощью РОР ионов $\mathrm{He}^{+}$ с энергией $1.7 \mathrm{MэB} \mathrm{в} \mathrm{режиме} \mathrm{максимального} \mathrm{отклоне-}$ ния зондирующего пучка от направления каналирования („random“). Анализ методом электронной микроскопии проводился в просвечивающем (ПЭМ), сканирующем (СЭМ) и высокоразрешающем (ВРЭМ) режимах на микроскопе JEM-2200FS при ускоряющем напряжении 200 кэВ с точечным разрешением 0.19 нм. Для определения состава и элементного распределения атомов в имплантированной области использовались сканирующий просвечивающий режим микроскопа и энергодисперсионная рентгеновская спектроскопия. Использовался размер зондирующего пучка 5С. Сигнал регистрировался рентгеноспектральным электронно-зондовым анализатором EX-230BU. Разрешение по энергии составляло 133 эВ.

\section{3. Результаты}

На рис. 1 представлены спектры РОР, зарегистрированные от образцов со слоем $\mathrm{SiO}_{2}$, имплантированным ионами $\mathrm{In}^{+}$и $\mathrm{As}^{+}$, до и после отжига при $T_{a}=800-1100^{\circ} \mathrm{C}$. В спектрах наблюдаются пики, обусловленные рассеянием ионов $\mathrm{He}^{+}$на атомах In и As. С ростом температуры отжига форма пиков изменяется. Пики, обусловленные рассеянием на атомах индия, при температурах отжига выше $900^{\circ} \mathrm{C}$ смещаются относительно своего первоначального положения в сторону больших значений номеров каналов (см. вставку к рис. 1). Наблюдаемые эффекты связаны с перераспределением имплантированных атомов в процессе отжига.

На рис. 2 представлены профили распределения атомов In и As, рассчитанные из соответствующих „random“ спектров POP с использованием программы RUMP. Как

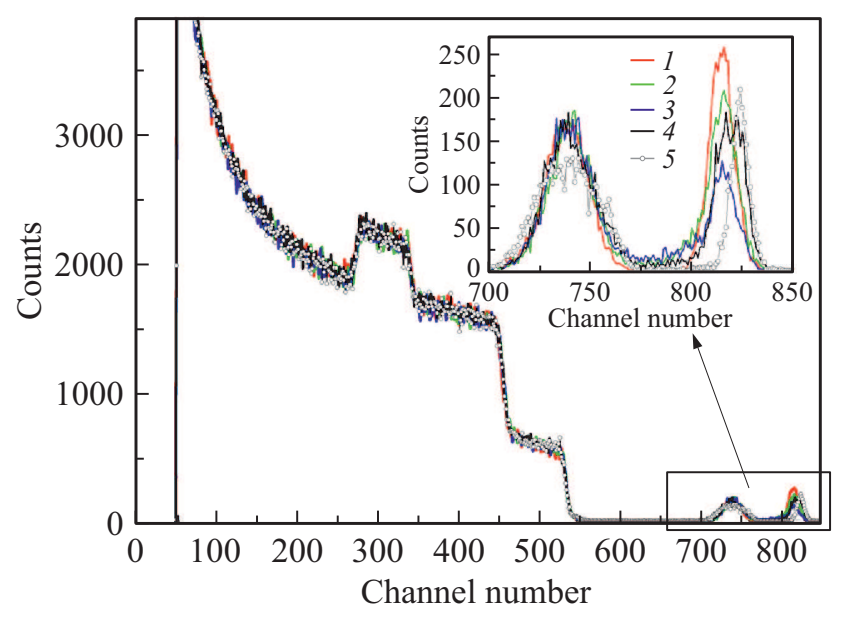

Рис. 1. Спектры РОР ионов $\mathrm{He}^{+}$с энергией $1.7 \mathrm{MэB} \mathrm{на} \mathrm{атомах}$ индия и мышьяка, полученные в условиях максимального отклонения от оси $\langle 100\rangle$ кремния для термически выращенных пленок $\mathrm{SiO}_{2}$, имплантированных ионами $\mathrm{In}^{+}$с энергией 50 кэВ дозой $4 \cdot 10^{15} \mathrm{~cm}^{-2}$ и $\mathrm{As}^{+}$с энергией 135 кэВ дозой $1 \cdot 10^{16} \mathrm{~cm}^{-2}$, до $(1)$ и после $(2-5)$ отжига в течение $30 \mathrm{мин}$ в атмосфере $\mathrm{N}_{2}$ при температуре $T,{ }^{\circ} \mathrm{C}: 2-800,3-900$, $4-1000,5-1100$. 
видно из рисунка, сразу после имплантации профили распределения имплантированных атомов имеют форму распределения Гаусса с максимальной концентрацией $\sim 1.3$ и $\sim 1.7$ ат\% на глубинах около 40 и $90 \mathrm{Hм}$ соответственно для атомов In и As. При этом измеренная интегральная концентрация внедренных атомов соответствовала дозе имплантированных ионов. После отжига при температурах 800 и $900^{\circ} \mathrm{C}$ пространственное распределение атомов As сохраняет форму распределения Гаусса, а положение максимума распределения и величина ширины профиля на половине высоты оста-

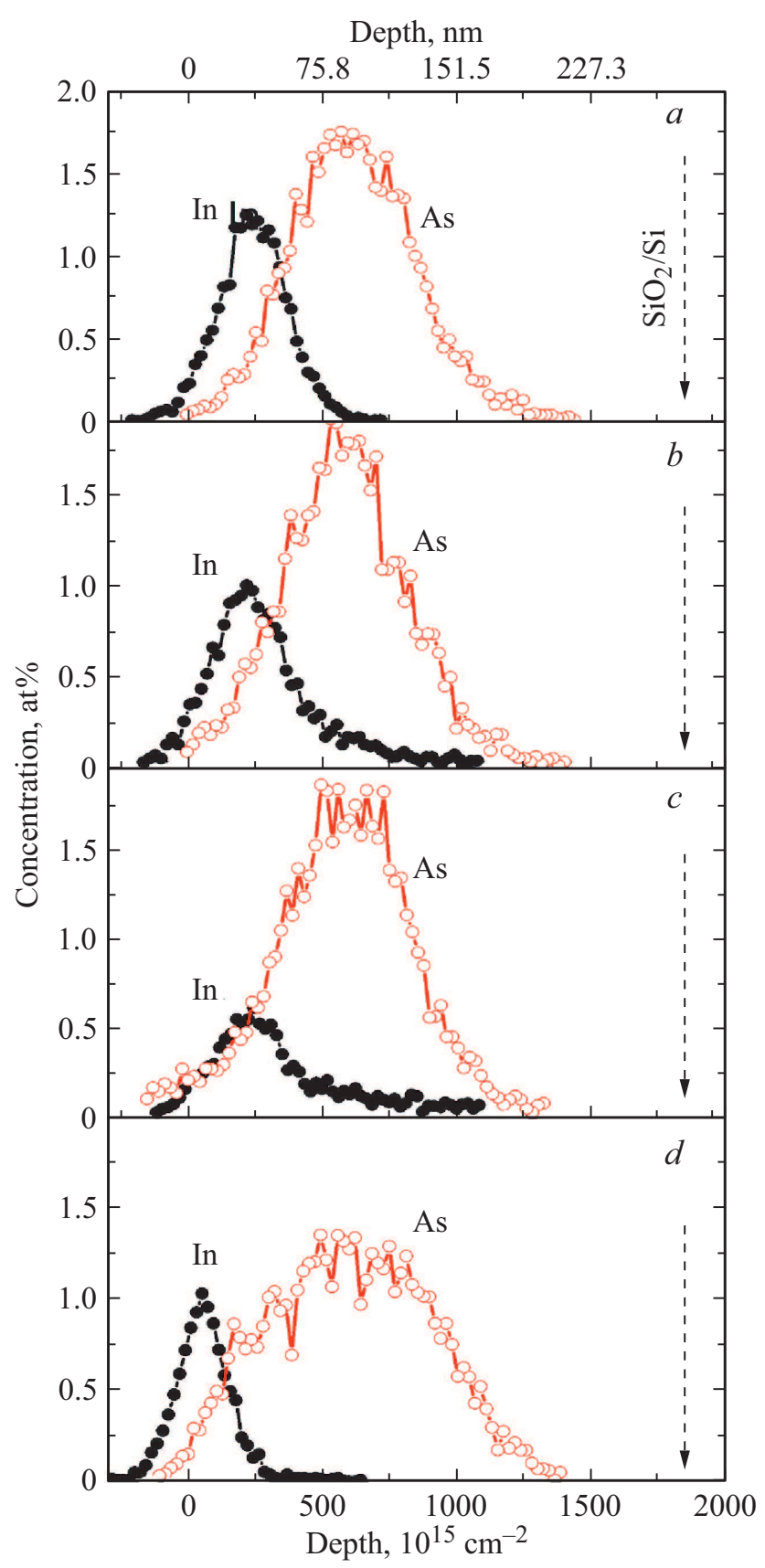

Pис. 2. Профили распределения атомов In и As, полученные в результате обработки спектров РОР до $(a)$ и после $(b-d)$ отжига при температуре, ${ }^{\circ} \mathrm{C}: b-800, c-900, d-1100$.

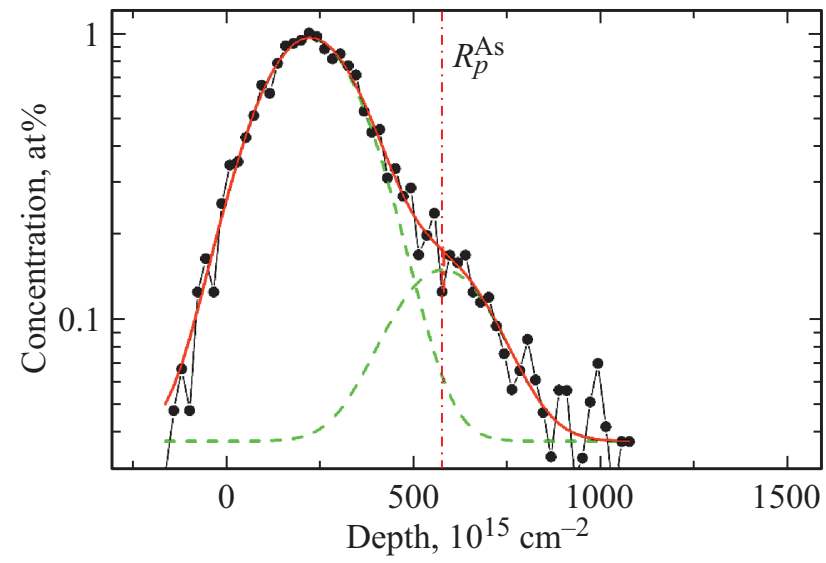

Рис. 3. Профиль индия, полученный после отжига при $900^{\circ} \mathrm{C}$, в разложении на составляющие пики распределения Гаусса. Вертикальной штрихпунктирной линией показан средний проецированный пробег ионов $\mathrm{As}^{+}$.

ются практически неизменными. Полная концентрация атомов As также сохраняется на прежнем уровне. В распределении атомов In после отжига при $T=800^{\circ} \mathrm{C}$ часть имплантированных атомов перераспределяется из области средних пробегов в глубь пленки $\mathrm{SiO}_{2}$. Разложение экспериментально измеренного профиля на составляющие пики распределения Гаусса показано на рис. 3. Из рисунка видно, что экспериментально наблюдаемое распределение индия становится бимодальным и хорошо описывается суперпозицией двух профилей в форме распределения Гаусса с максимумами на глубинах, равных $R_{p}^{\mathrm{In}}$ и $R_{p}^{\mathrm{As}}$. При этом доля атомов In на глубине средних пробегов ионов мышьяка составляет около $10 \%$ от общей концентрации имплантированных ионов индия. Интегральная концентрация атомов индия соответствует дозе имплантированных ионов. Дальнейшее увеличение температуры отжига до $900^{\circ} \mathrm{C}$ (рис. 2, c) сопровождается, с одной стороны, увеличением доли диффундирующих в глубь атомов индия, а с другой - уменьшением интегральной концентрации индия в диапазоне измеренных глубин в 1.7 раза. Отжиг при температуре $1000^{\circ} \mathrm{C}$ (на рисунке не показано) приводил к тому, что в пространственном распределении мышьяка появлялась небольшая асимметрия в области меньших глубин. При этом основной максимум распределения оставался на глубине средних пробегов ионов $\mathrm{As}^{+}$. Профиль атомов индия вновь становился одномодальным в форме распределения Гаусса. Но его максимум смещался в сторону поверхности $\mathrm{SiO}_{2}$ на глубину $\sim 20$ нм. При этом интегральная концентрация индия вновь возрастала и составляла $\sim 90 \%$ от первоначально имплантированных атомов. Увеличение температуры отжига до $1100^{\circ} \mathrm{C}$ (рис. $2, d)$ приводит к диффузионному уширению профиля мышьяка. Ширина профиля на половине высоты увеличивается в 2 раза, а концентрация в максимуме распределения уменьшается в 1.3 раза. Максимум распределения атомов In теперь смещается к поверхности 
$a$

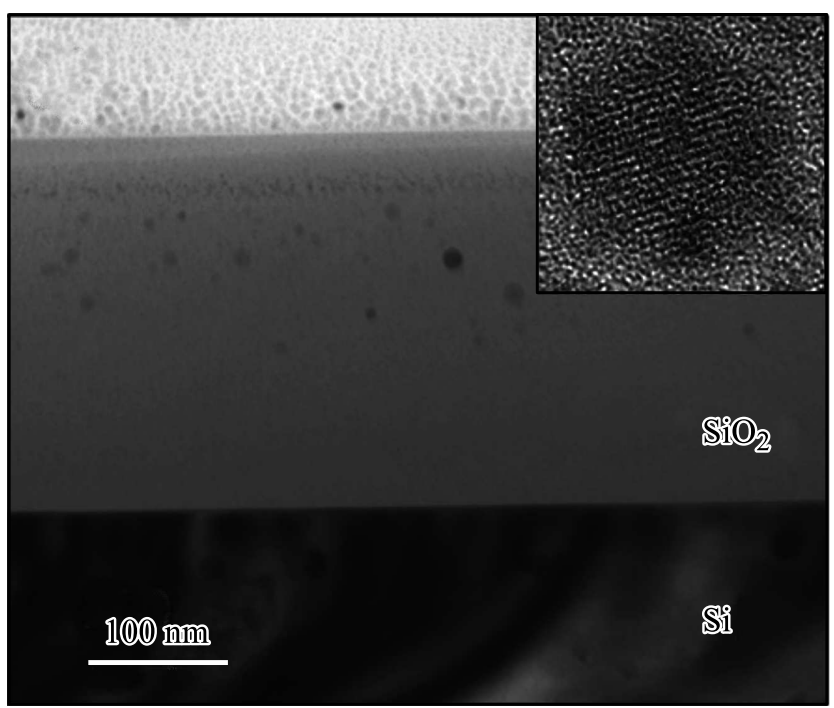

$b$

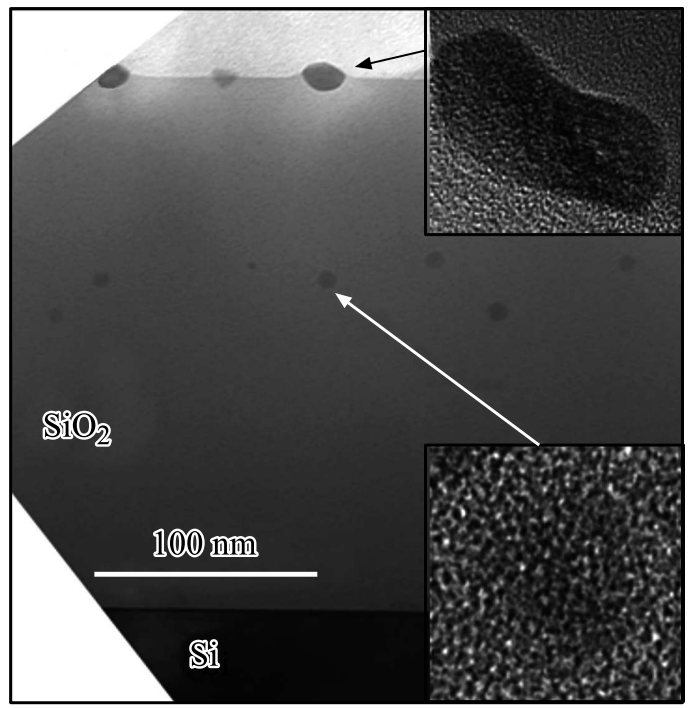

Рис. 4. Электронно-микроскопическое изображение поперечного среза пленок $\mathrm{SiO}_{2}$ на кремниевой подложке, имплантированных ионами $\mathrm{In}^{+}$и $\mathrm{As}^{+}$после отжига при температуре $900(a)$ и $1100^{\circ} \mathrm{C}(b)$ и соответствующие изображения отдельных нанокристаллов.

пленки $\mathrm{SiO}_{2}$. Полная концентрация индия при этом уменьшается в 1.5 раза.

На рис. 4 представлены электронно-микроскопические изображения поперечного среза образцов со слоем $\mathrm{SiO}_{2}$, имплантированным ионами $\mathrm{As}^{+}$и $\mathrm{In}^{+}$, после отжига при температурах 900 и $1100^{\circ} \mathrm{C}$. Из рис. 4, $a$ видно, что после отжига при $T=900^{\circ} \mathrm{C}$ на глубине средних пробегов ионов $\mathrm{As}^{+}$в пленке оксида кремния формируются преципитаты сферической формы, диаметр которых составляет 3-5 нм. В области средних пробегов ионов $\mathrm{In}^{+}$также наблюдается контрастная полоса, однако никакие крупные включения новой фазы в ней не формируются. Анализ методом высокоразрешающей электронной микроскопии нанокластеров, формирующихся на глубине $\sim R_{p}^{\mathrm{As}}$, показывает, что они имеют кристаллическую структуру (см. вставку к рис. 4, a). При увеличении температуры отжига до $1100^{\circ} \mathrm{C}$ плотность нанокластеров на глубине, близкой к $R_{p}^{\mathrm{As}}$, уменьшается. При этом большинство нанокластеров имеет неупорядоченную структуру, а средние размеры нанокластеров составляют $\sim 7$ нм. На поверхности пленки $\mathrm{SiO}_{2}$ происходит формирование продолговатых нанокристаллов, средняя длина которых составляет $\sim 20$ нм, а ширина $\sim 10$ нм.

На рис. 5 представлен ЭДС спектр поперечного среза образца, облученного ионами $\mathrm{As}^{+}$и $\mathrm{In}^{+}$после отжига при температуре $900^{\circ} \mathrm{C}$. В спектре четко наблюдаются пики О $K a$ вблизи 0.525 кэВ, Si Ka вблизи 1.740 кэВ, As $K a$ вблизи 10.535 кэВ, As $L a$ вблизи 1.282 кэВ и In $L a$ вблизи 3.285 кэВ. Аналогичный спектр был получен и от поперечных срезов образцов, отожженных при температуре $1100^{\circ} \mathrm{C}$.

С целью изучения корреляции между микроструктурой пленок и качественным распределением индия

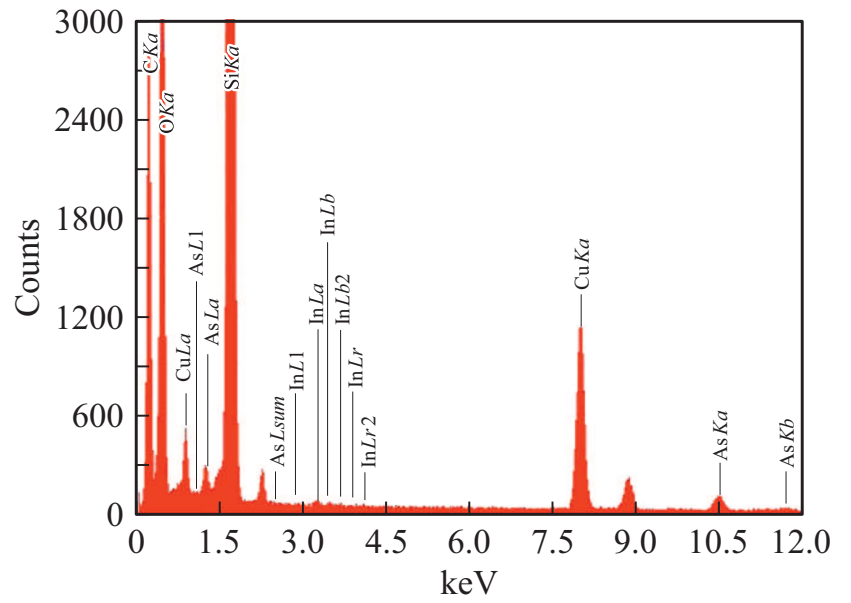

Рис. 5. Энергодисперсионный рентгеновский спектр поперечного среза образца, облученного ионами $\mathrm{In}^{+}$и $\mathrm{As}^{+}$после отжига при $T=900^{\circ} \mathrm{C}$.

и мышьяка в образцах, отожженных при температуре $900^{\circ} \mathrm{C}$, были получены СЭМ-изображение (рис. 6,a) и карты распределения химических элементов участка поперечного среза, соответствующие наблюдаемым пикам As $L a$ (рис. 6, $b$ ) и In $L a$ (рис. 6, c). Из сопоставления СЭМ-изображения и карт распределения мышьяка и индия видно, что после отжига при $T=900^{\circ} \mathrm{C}$ часть имплантированного мышьяка находится в области средних пробегов в виде скоплений, размеры и плотность которых соответствуют нанокристаллам, представленным на рис. 4, $a$. Атомы индия при этом в основном сосредоточены вблизи области средних пробегов их ионов в дисперсном состоянии. 

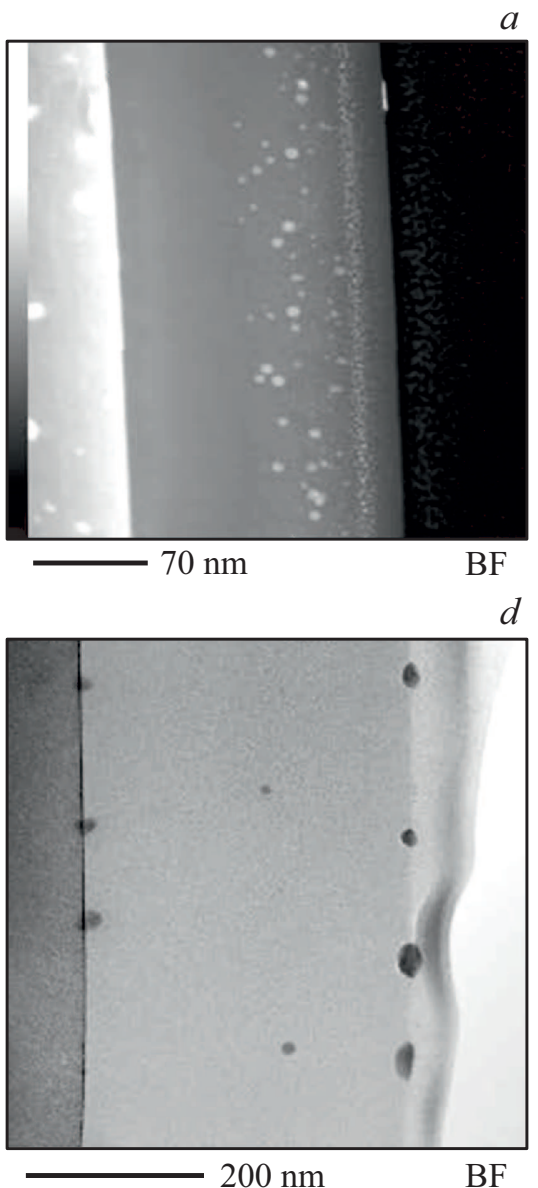

$\mathrm{BF}$

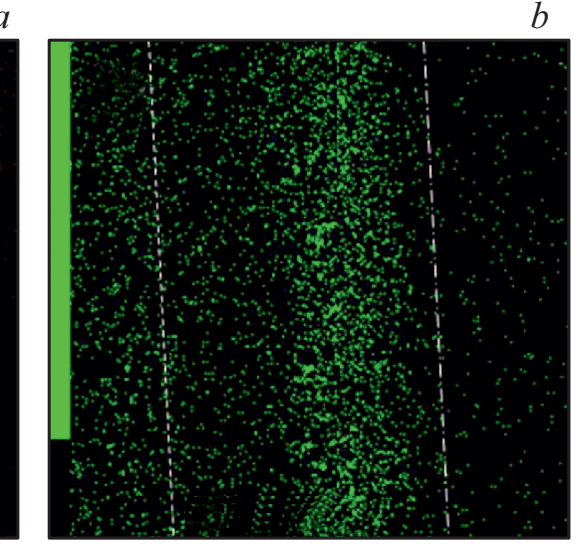

$70 \mathrm{~nm}$

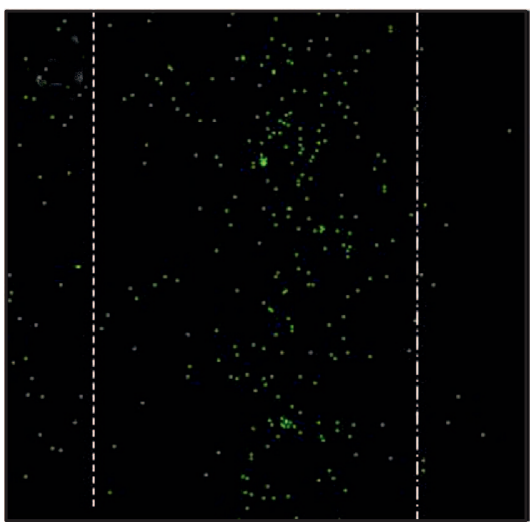

$200 \mathrm{~nm}$

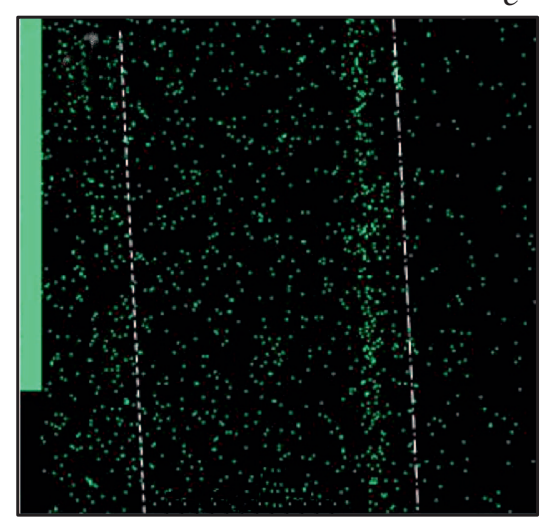

$70 \mathrm{~nm}$

$\operatorname{In} L$

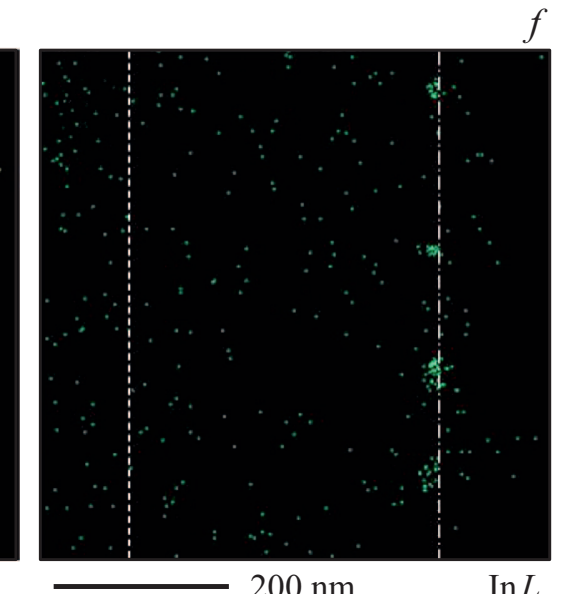

Рис. 6. Электронно-микроскопические изображения в режиме сканирования $(a, d)$ и карты распределения мышьяка $(b, e)$ и индия $(c, f)$ на поперечном срезе образцов, облученных ионами $\mathrm{In}^{+}$и $\mathrm{As}^{+}$после отжига при $T,{ }^{\circ} \mathrm{C}: a-c-900$ и $d-f-1100^{\circ} \mathrm{C}$.

На рис. 6, $d-f$ представлены СЭМ-изображение и карты распределения химических элементов, соответствующие пикам As $K a$ и In $L a$ соответственно, полученные на поперечных срезах образцов, отожженных при температуре $1100^{\circ} \mathrm{C}$. Видно, что увеличение температуры отжига приводит к резкому уменьшению концентрации атомов и индия, и мышьяка в области имплантации. Плотность нанокластеров мышьяка в пленке $\mathrm{SiO}_{2}$ также резко падает, а на поверхности пленки $\mathrm{SiO}_{2}$ формируются нанокластеры индия, размеры и форма которых соответствуют параметрам нанокристаллов, представленных на рис. $4, b$.

\section{4. Обсуждение}

Поведение In и As в ионно-имплантированной матрице $\mathrm{SiO}_{2}$ является весьма сложным. Атомы индия, имплантированные в $\mathrm{SiO}_{2}$, могут находиться в трех химических состояниях [15]. В тетраэдрическом состоянии, когда атомы In четырежды координированы атомами кислорода, индий является практически неподвижным. В присутствии водорода атомы индия могут образовывать нейтральный, не связанный с решеткой, комплекс
InOH, который обладает высокой подвижностью в матрице $\mathrm{SiO}_{2}$. Третье состояние, в котором индий также сильно подвижен, представляет собой форму связанного с решеткой одновалентного межузельного атома. В этом случае атомы индия могут диффундировать по межузельному механизму и энергия активации такого процесса составляет $\sim 2$ эВ [15]. По мнению авторов работы [15], именно этот процесс является ответственным за испарение индия из $\mathrm{SiO}_{2}$ и уширение профиля имплантированных ионов $\mathrm{In}^{+}$в форме распределения Гаусса в процессе постимплантационного отжига. Выражение коэффициента диффузии в этом случае имеет вид

$$
D_{\mathrm{In} / \mathrm{SiO}_{2}}=7 \cdot 10^{-6} \exp \left(-2.0{ }_{\ni} \mathrm{B} / k T\right)\left(\mathrm{cm}^{2} / \mathrm{c}\right),
$$

где $k$ - постоянная Больцмана. При высоких температуpax отжига $\left(\geq\left(1000^{\circ} \mathrm{C}\right)\right.$ In диффундирует к поверхности, где сегрегирует, а потом испаряется из образца [15]. При этом доля сегрегировавшего к поверхности и затем испарившегося индия сильно зависит от дозы имплантированных ионов. Например, для дозы $10^{15} \mathrm{In}^{+} / \mathrm{cm}^{2}$ после отжига при $T=1000^{\circ} \mathrm{C}$ в течение 30 мин в атмосфере $\mathrm{N}_{2}$ индий практически полностью испарился из образца, в то время как для дозы $10^{16} \mathrm{In}^{+} / \mathrm{cm}^{2}$ 
максимум концентрации индия наблюдался в области, которая максимально повреждена ионами. Это означает, что в ионно-имплантированном оксиде кремния для индия существуют по крайней мере два конкурирующих стока, а именно поверхность $\mathrm{SiO}_{2}$ и дефекты в объеме $\mathrm{SiO}_{2}$. В наших экспериментах, как это видно из рис. 2 и 6, стоками для атомов индия могут быть и преципитаты мышьяка, формирующиеся в процессе отжига при температурах $800-900^{\circ} \mathrm{C}$ на глубине средних пробегов ионов $\mathrm{As}^{+}$. Действительно, в работе [16] было высказано предположение о том, что в оксиде кремния зарождение фазы InSb происходит путем формирования преципитатов $\mathrm{Sb}$ и последующей диффузией к ним атомов In.

Положение атомов мышьяка в матрице $\mathrm{SiO}_{2}$ определяется концентрацией оборванных $\mathrm{Si}-\mathrm{O}$ связей. В процессе отжига имплантированной пленки атомы мышьяка встраиваются в сетку $\mathrm{SiO}_{2}$. В отсутствие поступления кислорода извне в пленке $\mathrm{SiO}_{2}$ формируются $\equiv \mathrm{Si}-\mathrm{As}{ }^{\bullet}-\mathrm{Si} \equiv$ центры, так называемые кислородные вакансии, в которых атом мышьяка имеет один неспаренный электрон [17]. В этом состоянии атомы мышьяка обладают низкой диффузионной способностью. В присутствии избыточного кислорода атомы мышьяка формируют $\mathrm{Si}-\mathrm{O}-$-вязи и встраиваются в замещающее положение, в котором они четырежды координированы атомами кислорода. В этом случае мышьяк обладает высокой подвижностью, поскольку может быть вытеснен из узла атомом кремния. Следует подчеркнуть, что аналогичный эффект наблюдается и в том случае, когда в пленку вместо избыточного кислорода поступает избыточный азот [14]. В наших экспериментах ускорение диффузии мышьяка наблюдалось при температурах отжига $\geq 1000^{\circ} \mathrm{C}$. Причем после отжига при $T=1000^{\circ} \mathrm{C}$ заметная диффузия наблюдалась лишь в области, прилегающей к поверхности пленки (см. вставку к рис. 1). Этот эффект может быть обусловлен тем, что при высоких температурах из атмосферы отжига происходит поступление атомов азота и остаточного кислорода, а также высвобождение кислорода на глубине $R_{p}^{\text {In }}$ за счет сегрегации индия к поверхности $\mathrm{SiO}_{2}$. При температуре $1100^{\circ} \mathrm{C}$ этот эффект усиливается и диффузионное расширение профиля As происходит симметрично. Из рис. 2, $d$ можно оценить коэффициент диффузии мышьяка, аппроксимируя экспериментально полученный профиль распределением Гаусса. Полная ширина профиля на половине высоты Гаусса в этом случае составляет 128 нм. Ширина профиля на половине высоты сразу после имплантации (рис. 2,a) составляет 68 нм. Такое уширение профиля за времена отжига 30 мин может быть достигнуто за счет коэффициента диффузии мышьяка $3.2 \cdot 10^{-14} \mathrm{~cm}^{2} / \mathrm{c}$. Это в $\sim 5$ раз больше значения $6.8 \cdot 10^{-15} \mathrm{~cm}^{2} / \mathrm{c}$, полученного из выражения [14]:

$$
D_{\mathrm{As} / \mathrm{SiO}_{2}}=3 \cdot 10^{-4} \exp (-2.9 \text { эВ } / k T)\left(\mathrm{cm}^{2} / \mathrm{c}\right) \text {. }
$$

Согласно имеющимся литературным данным $[14,18,19]$, диффузионные свойства атомов мышьяка в оксиде кремния зависят от их концентрации. Мышьяк ускоренно диффундирует, если его концентрация не превышает $10^{19} \mathrm{~cm}^{-2}$, а при концентрациях выше $10^{19} \mathrm{~cm}^{-2}$ он практически неподвижен. Объяснение этого эффекта может быть связано с тем, что при больших концентрациях, когда расстояние между имплантированными атомами сопоставимо с длиной их диффузии, происходит процесс гомогенного зарождения преципитатов As. Действительно, в наших экспериментах этот процесс наблюдался при температурах отжига 800 и $900^{\circ} \mathrm{C}$ (рис. 5 и 6), когда диффузионная длина атомов мышьяка даже в соответствии с выражением (2) составляет $1.1 \cdot 10^{-7}$ и $4.6 \cdot 10^{-7}$ см соответственно. Расстояние между внедренными атомами мышьяка при концентрациях $\sim 1.7$ ат\% составляет $\sim 1 \cdot 10^{-7}$ см. В работе [20] процесс сегрегации мышьяка в захороненных пленках оксида кремния происходил вплоть до температур $1405^{\circ} \mathrm{C}$. В наших экспериментах преципитаты As стабильны лишь до температур ниже $1100^{\circ} \mathrm{C}$. Этот эффект так же может быть объяснен высвобождением кислорода из связанного состояния при сегрегации индия на поверхности и последующей его диффузией в глубь пленки $\mathrm{SiO}_{2}$, где происходит взаимодействие атомов $\mathrm{O}$ и As, приводящее к ускорению диффузии последнего. Коэффициент диффузии кислорода в пленках аморфного оксида кремния даже при температуре $1000^{\circ} \mathrm{C}$ составляет $\sim 4 \cdot 10^{-15} \mathrm{~cm}^{2} / \mathrm{c}[21]$. При использованных нами временах отжига это соответствует диффузионной длине $\sim 2.7 \cdot 10^{-6} \mathrm{cм}$, что сопоставимо с расстоянием между средними проецированными пробегами ионов $\operatorname{In}^{+}$и $\mathrm{As}^{+}$.

\section{5. Заключение}

Изучено пространственное распределение и взаимодействие атомов In и As, имплантированных в термически выращенные пленки $\mathrm{SiO}_{2}$ толщиной $\sim 280$ нм. Ионы $\mathrm{As}^{+}$с энергией 135 кэВ дозой $1 \cdot 10^{16} \mathrm{~cm}^{-2}$ и $\mathrm{In}^{+}$с энергией 50 кэВ дозой $4 \cdot 10^{15} \mathrm{~cm}^{-2}$ создавали профили в форме распределения Гаусса с концентрацией на глубине средних проецированных пробегов $\sim 1.5$ ат\%. При этом средний проецированный пробег ионов $\mathrm{As}^{+}$был в 2 раза больше, чем пробег ионов $\mathrm{In}^{+}$. Методы резерфордовского обратного рассеяния, электронной микроскопии и энергодисперсионной рентгеновской спектроскопии были использованы для анализа пространственного распределения имплантированных атомов и структурных свойств пленок до и после отжига при температуре $800-1100^{\circ} \mathrm{C}$ в течение 30 мин в потоке паров азота. Установлено, что после отжига при $T=800-900^{\circ} \mathrm{C}$ происходит сегрегация атомов As на глубине средних пробегов и формирование нанокристаллов As, которые являются стоками для атомов In. Увеличение температуры отжига до $1100^{\circ} \mathrm{C}$ приводит к диффузии и сегрегации атомов In на поверхности $\mathrm{SiO}_{2}$ и одновременной ускоренной диффузии атомов мышьяка из области имплантации с коэффициентом $D_{\mathrm{As}}=3.2 \cdot 10^{-14} \mathrm{~cm}^{2} / \mathrm{c}$. 
Особенности диффузионных свойств атомов индия и мышьяка рассматриваются с точки зрения их положения в матрице $\mathrm{SiO}_{2}$.

\section{Благодарности}

Авторы выражают благодарность В.К. Васильеву за проведение имплантации ионами $\mathrm{In}^{+}$, П.Л. Смирнову за проведение имплантации ионами $\mathrm{As}^{+}$, А.Г. Черкову за помощь при исследовании образцов методом электронной микроскопии и энергодисперсионной рентгеновской спектроскопии.

\section{Финансирование работы}

Работа выполнена в рамках проекта Министерства образования и науки РФ (ГЗ 0306-2019-0005).

\section{Конфликт интересов}

У авторов нет конфликта интересов.

\section{Список литературы}

[1] H. Ko, K. Takei, R. Kapadia, S. Chuang, H. Fang, P.W. Leu, K. Ganapathi, E. Plis, H.S. Kim, S.-Y. Chen, M. Madsen, A.C. Ford, Y.-L. Chueh, S. Krishna, S. Salahuddin, A. Javey. Nature, 468, 286 (2010).

[2] A.C. Ford, C.W. Yeung, S. Chuang, H.S. Kim, E. Plis, S. Krishna, C. Hu, A. Javey. Appl. Phys. Lett., 98, 113105 (2011).

[3] K. Takei, R. Kapadia, H. Fang, E. Plis, S. Krishna, A. Javey. Appl. Phys. Lett., 102, 153513 (2013).

[4] S. Prucnal, Sh. Zhou, X. Ou, S. Facsko, M.O. Liedke, F. Bregolin, B. Liedke, J. Grebing, M. Fritzsche, R. Hubner, A. Mucklich, L. Rebohle, M. Helm, M. Turek, A. Drozdziel, W. Skorupa. J. Appl. Phys., 115, 074306 (2014).

[5] C. Hilsum, A.C. Rose-Innes. Semiconducting III-V compounds, ed. by H.R. Henisch (Oxford-London-N.-Y.-Paris, Pergamon Press, 1961) p. 254.

[6] В.И. Гавриленко, А.М. Грехов, Д.В. Корбутяк, В.Г. Литовченко. Оптические свойства полупроводников (Киев, Наук. думка, 1987).

[7] N.A. Viglin, V.V. Ustinov, S.O. Demokritov, A.O. Shorikov, N.G. Bebenin, V.M. Tsvelikhovskaya, T.N. Pavlov, E.I. Patrakov. Phys. Rev. B, 96, 235303 (2017).

[8] P. Madakson, E. Ganin, J. Karasinski. J. Appl.Phys., 67, 4063 (1990).

[9] C.W. White, J.D. Budai, J.G. Zhu, S.P. Withrow, M.J. Aziz. Appl. Phys. Lett., 68, 2389 (1996).

[10] C.W. White, J.D. Budai, J.G. Zhu, S.P. Withrow, R.A. Zuhr, D.M. Hembree, Jr., R.H. Magruder. J. Appl. Phys., 79, 1876 (1996).

[11] F.F. Komarov, O.V. Mil'chanin, L.A. Vlasukova, W. Wesch, A.F. Komarov, A.V. Mudryi. Bull. Rus. Acad. Sci. Phys., 74, 252 (2010).

[12] F. Komarov, L. Vlasukova, O. Milchanin, W. Wesch, E. Wendler, J. Zuk, I. Parkhomenko. Mater. Sci. Eng. B., 178, 1169 (2013).
[13] S. Prucnal, M. Turek, A. Drozdziel, K. Pyszniak, S.Q. Zhou, A. Kanjilal, W. Skorupa, J. Zuk. Appl. Phys. B, 101, 315 (2010).

[14] A.H. van Ommen. J. Appl. Phys., 56, 2708 (1984).

[15] A.H. van Ommen. J. Appl. Phys., 57, 5220 (1985).

[16] И.Е. Тысченко, М. Фельсков, А.Г. Черков, В.П. Попов. ФТП, 48, 1228 (2014).

[17] R.F. De Keersmaecker, D.J. Di Maria. J. Appl. Phys., 51, 1085 (1980).

[18] T. Yamaji, F. Ichikawa. J. Appl. Phys., 64, 2365 (1988).

[19] R. Singh, M. Maier, H. Kräutle, D.R. Young, P. Balk. J. Electrochem. Soc., 131, 2645 (1984).

[20] G.K. Celler, L.E. Trimble, K.W. West, L. Pfeiffer, T.T. Sheng. Appl. Phys. Lett., 50, 664 (1987).

[21] J.A. Costello, R.E. Tressler. J. Electrochem. Soc., 131, 1944 (1984).

Редактор А.Н. Смирнов

\section{Diffusion and interaction of In and As co-implanted in $\mathrm{SiO}_{2}$}

\author{
I.E. Tyschenko ${ }^{1}$, M. Voelskow ${ }^{2}$, A.N. Mikhaylov ${ }^{3}$, \\ D.I. Tetelbaum ${ }^{3}$
}

${ }^{1}$ Rzhanov Institute of Semiconductor Physics, Siberian Branch of Russian Academy of Sciences, 630090 Novosibirsk, Russia

${ }^{2}$ Institute of lon-Beam Physics and Materials Research, Helmholtz-Center Dresden-Rossendorf,

D-01314 Dresden, Germany

${ }^{3}$ Lobachevsky University,

603950 Nizhny Novgorod, Russia

Abstract The depth penetration as well as the interaction of In and As atoms ion-implanted in thermally-grown $\mathrm{SiO}_{2}$ films to the concentration of about 1.5 at $\%$ were investigated with Rutherford back-scattering spectrometry, electron microscopy and energydispersive spectroscopy as a function of annealing temperature at $800-1100^{\circ} \mathrm{C}$ in an nitrogen vapor flow. It was obtained that annealing at $T=800-900^{\circ} \mathrm{C}$ results in the segregation of As atoms at a depth corresponded to ion range and in the formation of As nanoclusters, which are the sinks for In atoms. The growth of the annealing temperature to $1100^{\circ} \mathrm{C}$ is accompanied by the $\mathrm{In}$ atom diffusion and segregation at the top $\mathrm{SiO}_{2}$ surface as well as by the enhanced diffusion of As atoms with the diffusion coefficient $D_{\text {As }}=3.2 \cdot 10^{-14} \mathrm{~cm}^{2} / \mathrm{s}$. 